\title{
Correction to: Hydraulic traits of co-existing conifers do not correlate with local hydroclimate condition: a case study in the northern Rocky Mountains, U.S.A
}

\author{
Tim Clute ${ }^{1}(1) \cdot$ Justin Martin ${ }^{1} \cdot$ Nate Looker ${ }^{2} \cdot$ Jia Hu$^{3}$
}

Published online: 17 February 2021

(c) Springer-Verlag GmbH Germany, part of Springer Nature 2021

\section{Correction to: Oecologia \\ https://doi.org/10.1007/s00442-020-04772-z}

The authors would like to correct errors in the original publication of their article.

The original article has been corrected.

In the Materials and methods section under the first paragraph of the "Study site and experimental design." The second sentence has the word 'Folk' which should be changed to 'Fork'. "To capture a hydroclimatic gradient associated with elevation, we selected two south-facing sub-catchments

Table 1 Estimates for $50 \%$ loss of conductivity $\left(P_{50}\right)$ and safety margins for $P$. ponderosa, $P$. menziesii, and $P$. engelmannii at the lowand high-elevation sites

\begin{tabular}{lll}
\hline Site-Species & Estimated $P_{50} \pm \mathrm{SE}$ & $\begin{array}{l}\text { Estimated } \\
\text { safety mar- } \\
\text { gins } \pm \mathrm{SE}\end{array}$ \\
\hline Low P. ponderosa & $-3.84 \pm 0.10^{\mathrm{a}}$ & $1.94 \pm 0.11^{\mathrm{a}}$ \\
Low P. menziesii & $-4.98 \pm 0.06^{\mathrm{b}}$ & $3.01 \pm 0.09^{\mathrm{b}}$ \\
High P. menziesii & $-4.89 \pm 0.08^{\mathrm{b}}$ & $2.95 \pm 0.10^{\mathrm{b}}$ \\
High P. engelmannii & $-4.12 \pm 0.05^{\mathrm{a}}$ & $2.58 \pm 0.06^{\mathrm{c}}$ \\
\hline
\end{tabular}

Superscript letters denote significant differences of $P<0.05$

The original article can be found online at https://doi.org/10.1007/ s00442-020-04772-z.

Tim Clute

ticlute@gmail.com

1 Department of Ecology, Montana State University, Bozeman, MT 59715, USA

2 Department of Soil, Water, and Climate, University of Minnesota, St. Paul, MN 55108, USA

3 University of Arizona, School of Natural Resources and the Environment, Tucson, AZ 85721, USA from low (1280 m.a.s.l., lat/long: 46.88210, - 113.34449) and high elevation (1800 m.a.s.l., lat/long: 46.89099, -113.29714) sites within the North Fork of the Elk Creek watershed."

In Table 1, everything should have a superscript. Currently, there is a subscript associated with the estimated $\mathrm{P}_{50}$ value of low P. menziesii. This should be a superscript.

Revised version of Acknowledgements section updated here.

Acknowledgements TC and all related research was supported by National Science Foundation grant number, DEB-1457720, the Montana National Science Foundation Established Program to Stimulate Competitive Research and the Montana Institute on Ecosystems. The manuscript is to be part of a Special Issue honoring Russ Monson. His true talent is his ability to bridge ecophysiology with many different disparate fields, from plant biochemistry to ecosystem ecology. Russ has always excelled at identifying the pressing and novel scientific questions and creating a comprehensive and creative research plan to address those issues. We would also like to thank Dave Roberts, Yuriko Yano, Chase Dart, Jim Junker, Corinne Moss, and Claire Qubain with help on data collection and helpful discussions. 